\title{
Association of rs1057035polymorphism in microRNA biogenesis pathway gene (DICER1) with azoospermia among Iranian population
}

\author{
Sahar Moghbelinejad1 · Reza Najafipour $1 \cdot$ Abdolmabood Momeni2 \\ * Sahar Moghbelinejad smoghbelinejad@qums.ac.ir \\ 1 Cellular and Molecular Research Centre, Qazvin University \\ of Medical Sciences, P. O. Box 341197-5981, Qazvin, Iran \\ 2 Biology-Genetic Department, School of Basic Science, Arak \\ University, Arak, Ira \\ Received: 1 May 2017 / Accepted: 10 August 2017 / Published online: 29 August 2017 \\ (C) The Genetics Society of Korea and Springer Science+Business Media B.V. 2017
}

\begin{abstract}
Since genes involved in microRNA biogenesis pathways have a main role in impaired spermatogenesis, in this research, we evaluated different genotypes frequency of seven single-nucleotide polymorphisms in DICER 1 and DROSHA genes. Different genotypes frequency of DICER1 (rs12323635, rs1057035, rs13078 and rs3742330) and DROSHA (rs10719, rs642321 and rs2291102) were determined by sequencing method in 385 infertile men and 120 fertile controls. It was found that $\mathrm{CC}$ genotype $(\mathrm{P}=0.000)$ and $\mathrm{C}$ allele $(\mathrm{P}=0.0)$ of rs $1057035 \mathrm{~T}>\mathrm{C}$ polymorphism were associated with idiopathic male infertility (azoospermia). Gene expression study in blood and testis samples was done by real time PCR technique. Our results showed significant under expression of DICER1 gene in blood and testis tissues of azoospermic samples ( $\mathrm{P}<0.05)$, but we did not observed significant difference in expression ratio between infertile men with and without $\mathrm{C}$ allele of rs 1057035 SNP $(\mathrm{P}>0.05)$. The results of this study showed that among the studied variants, only one of them in DICER1 might be associated with azoospermia, but additional studies needs in different populations and ethnics.
\end{abstract}

Keywords DICER1 - DROSHA · Polymorphisms · Male Infertil 